\title{
Protocol for Management of Hyperthyroidism by Radioactive Iodine (RAIT)-SNMB Guidelines
}

\author{
Fatima Begum 1 , Sadia Sultana ${ }^{2}$, Nurun Nahar ${ }^{2}$, Faridul Alam ${ }^{3}$, Mizanul Hasan ${ }^{2}$, Raihan Hussain ${ }^{2}$, \\ Mahmubul Haque ${ }^{4}$, Faria Nasreen1, Mohafizul Haque Khan ${ }^{5}$, Lutfun Nisa ${ }^{6}$, Fauzia Moslem ${ }^{7}$, Shahana \\ Afroz $^{8}$, Kamila Afroj Quadir ${ }^{2}$, M. A. Karim ${ }^{9}$ \\ ${ }^{1}$ Associate Professor, NINMAS, BAEC, ${ }^{2}$ Professor, NINMAS, BAEC, ${ }^{3}$ Director, BIHS, ${ }^{4}$ Director, INMAS, \\ Mitford, BAEC, ${ }^{5}$ Director, NINMAS, BAEC, ${ }^{6}$ Former Professor, NINMAS, ${ }^{7}$ Head, Dept. of Radiology and \\ Imaging, BIHS, ${ }^{8}$ Member, Bangladesh Atomic Energy Regulatory Authority, ${ }^{9}$ Former Chairman, BAEC
}

Radioactive iodine therapy (RAIT) has been being a successful mode of treatment for hyperthyroidism since its use on 1941 in United State of America. Former Institute of Nuclear Medicine, Bangladesh Atomic Energy Commission first started the RAIT on 1981. Thereafter other Nuclear Medicine Centers have been practicing RAIT on hyperthyroidism. In this background, there was a need for uniformity of RAIT management protocol for hyperthyroidism. Society of Nuclear Medicine, Bangladesh (SNMB)-2002 had taken an initiative. A protocol for RAIT management for hyperthyroidism had been decided on daylong workshop on 14 August 2002 organized by SNMB with the consensus of specialists of Nuclear Medicine, Endocrinologists, Medicine Specialists and ENT Surgeons.

These guidelines for management of hyperthyroidism by RAIT was upgraded based on recent knowledge, clinical and practical experiences and decided on a seminar, 26 February 2015 by SNMB held in National Institute of Nuclear Medicine and Allied Sciences (NINMAS) auditorium.

\section{Thyrotoxicosis}

Thyrotoxicosis refers to clinical syndrome that results from metabolic effects of excess thyroid hormone at the tissue level, regardless of the etiology. [Wartofsky 1996, Woeber 1999]

\section{Etiologies of thyrotoxicosis}

1. Hyperthyroidism- Graves' disease, single toxic nodular goiter (STNG), toxic multinodular goiter (TMNG)

2. Thyroiditis

3. Factitious ingestion of thyroid hormone

4. Ectopic thyroid hormone production Struma ovarri

5. Drug induced- over iodine, amiodarone, lithium, interferon $\alpha$, thalidomide

6. TSH induced- TSH secreting pituitary adenoma, choriocarcinoma and hydatidiform mole, follicualr carcinoma of thyroid with or without metastases.

\section{Hyperthyroidism}

It is due to inappropriately high synthesis and secretion of thyroid hormones by the thyroid gland.

\section{Categories of hyperthyroidism:}

1. Graves' disease (GD)

2. Single Toxic Nodular Goiter (STNG)/Solitary Toxic Nodule (STN)/Toxic adenoma (TA)/ solitary thyroid adenoma (STA)/Autonomous Functioning Toxic Nodule (AFTN)/ Autonomous Toxic Nodule (ATN)

3. Toxic multinodular goiter (TMNG) 


\section{Diagnosis of hyperthyroidism depends on}

History

$>$ Clinical features

$>$ Investigations

\section{Investigations:}

1. Serum free triiodothyronine (FT3), free thyroxine (FT4) \& thyroid stimulating hormone (TSH).

2. ${ }^{131} \mathrm{I}$ thyroid uptake- at 2 hours and 24 hours by giving $5-10 \mu \mathrm{Ci}^{131} \mathrm{I}$ orally

3. ${ }^{99} \mathrm{~m}$ Technetium scan by giving $2 \mathrm{mCi}$ ${ }^{99 m} \mathrm{Tc} \mathrm{I} / \mathrm{V}$ and scan after 20-30 min

4. Ultrasound imaging and Color Doppler Study (CDS) of thyroid gland for

all patients of hyperthyroidism especially in pregnant women.

5. Thyrotropin receptor antibodies (TRAbs)-

a. Thyroid stimulating immuno globulins (TSI), thyrotropin-binding inhibitor immunoglobulin (not available at present)

b. Other antibodies -antit hyroglobulin antibody (anti $\mathrm{Tg} \mathrm{Ab}$ ), anti thyroid peroxidase antibodies (anti TPO Ab) to differentiate from thyroiditis.

6. Complete blood count (CBC)

7. Liver enzymes

${ }^{131}$ I thyroid uptake and ${ }^{99 m}$ Technetium scan are contraindicated in pregnancy and lactating mother

\section{Patient selection for RAIT}

1. Patient must be an established case of hyperthyroidism

2. Patient must be referred by physician for RAIT

3. Contraindicated in case of pregnancy and lactation

Indications for ${ }^{131}$ I therapy:

1. Established hyperthyroidism- mild cases of hyperthyroidism ${ }^{131}$ I may be given without pretreatment with antithyroid drug (ATD)

2. Following cases require pretreatment with ATD before RAIT:

a. Highly toxic patient (FT4- 2 to 3 times higher than normal level)

b. Cardiac patient

c. Patient with active ophthalmopathy

d. Old age

e. Low ${ }^{131}$ I uptake \& high serum FT4

f. Patient with very large goiter

Written consent should be taken before RAIT from each patient and in cases of children from guardian

\section{Pretreatment protocol for GD:}

a) Standard ATD-

a. Neomercazole- $15-45 \mathrm{mg} /$ day in 3 divided doses

b. Methimazole (MMI )- single dose 10$20 \mathrm{mg} /$ day,

c. Propylthiouracil (PTU ) 50-150 mg three times in a day

b) ATD must be adjusted according to hormone levels and should be continued until patient is mildly toxic or euthyroid.

c) When patient attains euthyroid or mildly hyperthyroid state,

a. Withdraw neomercazole 3-5 days before RAIT and resume 3-7 days after RAIT for 4-8 weeks.

b. In case of PTU drug should be withdrawn for one month before RAIT

d) Co-morbid conditions should be treated before RAIT

a. Active opthalmopathy will be treated by ophthalmologists- RAIT can be given in inactive state of opthalmopathy

b. For cardiac problems- consult with cardiologist for management before RAIT

Dose of ${ }^{131}$ I for Graves' disease -

- Modified fixed dose: 10-15 mCi (370-555 $\mathrm{MBq})$ 
Pretreatment for single toxic nodular goiter (STNG) \& Toxic multinodular goiter (TMNG)

- ATD is not preferred for treatment of STNG or TMNG but may be given as pretreatment when toxicity level is high, serum FT4 level-2-3 times higher than normal.

- Patient should be treated with RAIT once toxicity is controlled or reduced

Dose of ${ }^{131}$ I for STN

- 15-20 mCi (555-740 MBq) depending on gland size

Dose of ${ }^{131}$ I for TMNG

- 15-25 mCi (555-925 MBq) depending on gland size

Graves' disease in children

We give RAIT in children when toxicity is not controlled with ATD as well as those who are allergic to drugs.

Dose of ${ }^{131} \mathbf{I}$ for children

- 3-8 mCi (111-296 MBq)

Radiation protection advice following RAIT

Radiation Precaution for 5-7 days

a. No need of hospitalization

b. Avoid close contact with people especially pregnant women and children

c. Use separate bed

d. Drink plenty of fluid and void frequently after RAIT

e. Chew sour candy or citrus fruit or Vit C tablet after 24 hrs of RAIT

f. Flush toilet twice after use

g. Bath/shower everyday

h. Use separate utensils

i. Do not cook or feed a child

j. Avoid pregnancy for 6 months

\section{Follow up}

First follow up visit is at 3 months, if necessary come earlier.

Thereby 3 monthly follow up for first year and then biannually.

1. Consult patient \& give assurance
2. Serum FT3 or FT4 \& TSH estimation- treat and advice according to serum report.

3. Give symptomatic treatment for complaints, if necessary

4. Refer to other specialists for other medical problems.

(Any fluctuation state of thyroid function should be followed up closely)

\section{Outcome of RAIT}

- Euthyroid- Follow up

- Hypothyroid- Levothyroxine supplementation $1.7 \mu \mathrm{gm} / \mathrm{kg} /$ day

- Hyperthyroid- short course of ATD and if toxicity persists $2^{\text {nd }}$ therapy is recommended after 6 months.

- Lag behind TSH with normal FT3, FT4- FU for one year without treatment

$* * * 2^{\text {nd }} /$ consecutive dose of RAIT should be higher than the previous dose

\section{Thyroid Storm}

Thyroid storm is a rare complication if ${ }^{131} \mathrm{I}$ therapy due to rapid outpouring of thyroid hormones in blood secondary to radiation thyroiditis and sometimes-even death may occur. To avoid this condition, highly toxic patients are pretreated with anti-thyroid drugs to make them mild hyperthyroid or euthyroid. It may also induced by intercurrent illness especially infection.

\section{Management of thyroid storm:}

1. Carbimazole is administered at a dose of 20 $30 \mathrm{mg}$ every 4-6 hours.

2. Propanolol $1-2 \mathrm{mg} / \mathrm{min}$ IV every $15 \mathrm{~min}$ up to $\max 10 \mathrm{mg}, 40-80 \mathrm{mg}$ every $4-6 \mathrm{~h} \mathrm{IV}$ dose (initially if haemodynamically unstable) or Esmolol $50 \mu \mathrm{g} / \mathrm{kg} / \mathrm{min}$ IV - may increase by $50 \mu \mathrm{g} / \mathrm{kg} / \mathrm{min}$ every $4 \mathrm{~min}$ as required to a $\max$ of $300 \mu \mathrm{g} / \mathrm{kg} / \mathrm{min}$ (Short acting).

3. Iodine (saturated solution of potassium iodide) -5 drops $(0.25 \mathrm{ml}$ or $250 \mathrm{mg})$ orally every 6 hours. Do not start until 1 hour after antithyroid drugs. 
4. Hydrocortisone- $300 \mathrm{mg}$ intravenous load, then $100 \mathrm{mg}$ every 8 hours. Alternative drug: dexamethasone.

5. Other supportive measures should be takentreatment of CCF, tachycardia, rehydration, multivitamins and antibiotic

\section{Articles consulted:}

1. Alam F, Islam ASMM and Karim MA. Therapy Protocol for Thyroid carcinoma and Thyrotoxicosis with I-131 Adopted in the National Workshop on Management of Thyroid cancer \& Thyrotoxicosis by Nuclear Medicine Technique-A Consensus Report. Bangladesh J Nucl Med 2002; 5(2):39-42.

2. Bahn RC, Burch HB, Cooper DS, Garber JR, Greenlee C, Klein I, Laurberg P, Mc Dougall R, Montori VM, Rivkees SA, Ross DS, Sosa JA, Stan MN. Hyperthyroidism and Other Causes of Thyrotoxicosis Management Guidelines of the American Thyroid Association and American Association of Clinical Endocrinologists. Endocrine Pract. 2011;17(3):e1-65.

3. Barbesino $G$ and Tomer Y. Clinical Utility of TSH Receptor Antibodies. J Clin Endocrinol Metab 2013 Jun; 98(6): 22472255.

4. Flores-Rebollar A, Ruiz-Juvera A, LopezCarrasco $\mathrm{G}$ and Gonzalez-Trevino O. Effect of $1110 \mathrm{MBq}$ Radioiodine in Reducing Thyroid Volume in Multinodular Goiter: A New Protocol. J Clin Med Res. 2013 Jun; 5(3): 234-238.

5. Jaiswal AK, Bal C, Damle NA, Ballal S, Goswami R, Hari $\mathrm{S}$ and Kumar $\mathrm{P}$. Comparison of clinical outcome after a fixed dose versus dosimetry-based radioiodine treatment of Graves' disease: Results of a
6. randomized controlled trial in Indian population. Indian J Endocrinol Metab. 2014 Sep-Oct; 18(5): 648-654.

7. LégerJ, and Carel J C. Hyperthyroidism in Childhood: Causes, When and How to Treat. J Clin Res Pediatr Endocrinol. 2013 Mar; 5(Suppl 1): 50-56.

8. Lewis A, Atkinson B, Bell P, Courtney H, McCance D, Mullan K, and Hunter S. Outcome of 131I therapy in hyperthyroidism using a $550 \mathrm{MBq}$ fixed dose regimen. Ulster Med J. 2013 May; 82(2): 85-88.

9. Nwatsock JF, Taieb D, Tessonnier L, Mancini J, Dong-A-Zok F, and Mundler O. Radioiodine Thyroid Ablation in Graves' Hyperthyroidism: Merits and Pitfalls. World J Nucl Med. 2012 Jan-Jun; 11(1): 7-11.

10. Scott A Rivkees. Pediatric Graves' disease: management in the post-propylthiouracil Era. International Journal of Pediatric Endocrinology 2014, 2014: 10 http: //www. ijpeonline.com/content/2014/1/10.

11. Shivaprasad C and Kumar KMP. Long-term carbimazole pretreatment reduces the efficacy of radioiodine therapy. Indian $\mathrm{J}$ Endocrinol Metab. 2015 Jan-Feb; 19(1): 84 88 .

12. Strachan MWJ, Walker BR. Endocrine disease. In: Colledge NR, Walker BR, Ralston SR. Davidson's Principles \& Practices of Medicine.21 st Edition, China; Churchill Livingstone Elsevier 2010.

13. Wartofsky L.Treatment options for hyperthyroidism. Hospital practice 1996;Sep15:69-83.

14. Woeber KA. The year in review: the thyroid. Ann Intern Med 1999; 13:1959-962. 